\title{
Awareness on Pet Hygiene Among Pet Owners- A Survey
}

\author{
B.V.M. Anirudh ${ }^{1}$, Gayathri.R² and V.Vishnu Priya ${ }^{3}$ \\ ${ }^{1}$ Saveetha Dental College and Hospitals, Saveetha Institute of Medical \\ and Technical Sciences, Saveetha University, Chennai 77, India \\ ${ }^{2}$ Assistant Professor Department of Biochemistry Saveetha Dental College \\ and Hospitals, Saveetha Institute of Medical and Technical Sciences, Saveetha \\ University Chennai 77, India \\ ${ }^{3}$ Professor Department of Biochemistry Saveetha Dental College and Hospitals, \\ Saveetha Institute of Medical and Technical Sciences, Saveetha University, \\ Chennai 77, India
}

\section{ABSTRACT}

Nowadays, humans show interest towards taming pets. Most of the pet owners are not aware of the proper hygiene practices to be followed while taming a pet, which leads to various health complications to the pet as well as the owner. The aim of this study is to assess the awareness of pet hygiene among pet owners.A questionnaire was prepared about pet hygiene and was uploaded through surveyplanet. A total of 100 participants who own a pet have taken the survey. The results were obtained and statistically analysed through SPSS software, chi square test was done to check the association and a p value of 0.05 was said to be statistically significant. The survey was conducted in the month of May, 2020..From the survey, it was evident that dogs were the most prevalent type of pet seen in most households(65\%). In a question regarding the pets bath cycle, $63 \%$ of the participants bathe their pets once in 15 days, $26 \%$ of the participants bathe their pets once in 30 days, 7\% of the participants bathe their pets once in 2 months and 4\% participants bathe their pets very rarely. 79\% of the pet owners comb their pets.57\% participants reported that their pets had hairfall. 83\% of the participants toilet trained their pets. Even though pet owners are taking enough precautions, they are also taking risks by making their pets sleep with them, licking them. This survey has created awareness on the do's and don'ts when having a pet, improper hygiene of the pet may lead to illness of the pet as well as the owner.

KEY WORDS: PET; HYGIENE; INFECTION; BITE MARKS.

\section{INTRODUCTION}

Pet ownership is common today. Although the population varies by each region, studies indicate that in most of

\section{ARTICLE INFORMATION}

*Corresponding Author: gayathri.sdc@saveetha.com Received 24th July 2020 Accepted after revision 26th Sep 2020 Print ISSN: 0974-6455 Online ISSN: 2321-4007 CODEN: BBRCBA

Thomson Reuters ISI Web of Science Clarivate Analytics USA and Crossref Indexed Journal

\section{Clarivate
Analytics}

NAAS Journal Score 2020 (4.31) SJIF: 2020 (7.728)

A Society of Science and Nature Publication,

Bhopal India 2020. All rights reserved.

Online Contents Available at: http//www.bbrc.in/

Doi: http://dx.doi.org/10.21786/bbrc/13.8/186 the countries the majority of household's own pets. Cats and dogs were frequently owned pets, but other species were also reported(Slater et al., 2008; Perrin, 2009; Murray et al., 2010).Animal ownership and interaction isn't discouraged by healthcare professionals, as various studies have found out that the mental and physical perks of pet ownership and companionship(Friedmann and Son, 2009), seen mostly among children(Poresky and Hendrix, 1990; Melson, Schwarz and Beck, 1997), the elderly(Raina et al., 1999) and immunocompromised individuals such as in AIDS patients(Carmack, 1991; Conti et al., 1995; Castelli, Hart and Zasloff, 2001). Pet ownership could have positive effects on human health. 
Benefits ranged from higher survival rates from myocardial infarction(Friedmann et al., 1980; Anderson, Reid and Jennings, 1992), a reduced risk of asthma and hypersensitivity reaction in children exposed to pet allergens(Nafstad et al., 2001; Ownby, Johnson and Peterson, 2002) during the primary year of life, a reduced risk of cardiovascular disease and better physical and psychological wellbeing in community dwelling older people(Friedmann et al., 1980; Anderson, Reid and Jennings, 1992; Headey, 1999). Companionship with pets could be an important factor for proper mental health and well-being (Saunders et al., 2017). Bonding with pets provides benefits to those with psychological problems by offering emotional support .

Pet ownership is a modifiable environmental factor because it's our choice to own pets or not. A recent study showed that the human-dog interaction through dogs' human-like gazing behavior increased human oxytocin , which has received increasing attention for its role in promoting positive social behavior and stress regulation, and its potential as a therapeutic intervention for addressing various aspects of psychiatric disorders(Endo et al., 2020). There are also things which are caused by pets such as people can contract a cornucopia of diseases, including brucellosis, roundworm, skin mites, E. coli, salmonella, giardia, ringworms, and cat-scratch fever and pets are second only to late-night noise as a source of conflict between neighbors(Herzog, 2011). All these benefits can be maintained only if we maintain our pet hygiene. Nowadays, people with pets are increasing day by day and people are not aware of the complications of not maintaining proper pet hygiene. This survey aimed at evaluating and creating awareness on pet hygiene among pet owners.

\section{MATERIALS AND METHODS}

Study Design: A survey was conducted among 100 pet owners ,to evaluate their knowledge and awareness on pet hygiene. The participants did the survey voluntarily. Ethical approval and informed consent from the participants were obtained. The study was conducted in the month of may, 2020.

Survey Instrument: The survey instrument which was a questionnaire was prepared after extensive review of the existing literature. The questionnaire was reviewed and amendments were made to improve clarity of the questions to eliminate ambiguous responses. The questionnaire consisted a total of 12 questions. The questionnaire was shared to the participants using online survey platform.

Data Analysis: Only completed surveys were taken for analysis and the incomplete ones were eliminated. The statistical test used is descriptive statistics. All the responses obtained were tabulated and reliability of the data was checked. The statistics done using SPSS software, chi square test was done to check the association and a $p$ value of 0.05 was said to be statistically significant.

\section{RESULTS AND DISCUSSION}

A total of 100 pet owners have answered the survey. In a question pertaining to the type of pet owned commonly, dogs were the most prevalent type of pet seen in most households(65\%) (Figure-1). In a question regarding the pets bath cycle, $63 \%$ of the participants bathe their pets once in 15 days, $26 \%$ of the participants bathe their pets once in 30 days, $7 \%$ of the participants bathe their pets once in 2 months and $4 \%$ participants bathe their pets very rarely(Figure-2). 79\% of the pet owners comb their pets(Figure-3). Bathing and combing are done to avoid ticks and fleas on pets so that when in contact with pets, it doesn't get transmitted, ticks and fleas cause skin and hair disorders in both the pet and humans(Traversa, 2013). 57\% participants reported that their pets had hairfall (Figure-4). 83\% of the participants toilet trained their pets (Figure-5).

Figure 1: Pie chart showing distribution of responses to the question "What pet do you own" with Dog- 65\% being the majority of responses followed by Cat-17\%, Rabbit- 6\%, Bird- 5\% and 0thers- 7\%. Blue colour indicates dog, green indicates cat, yellow indicates rabbit, purple indicates bird and red indicates others

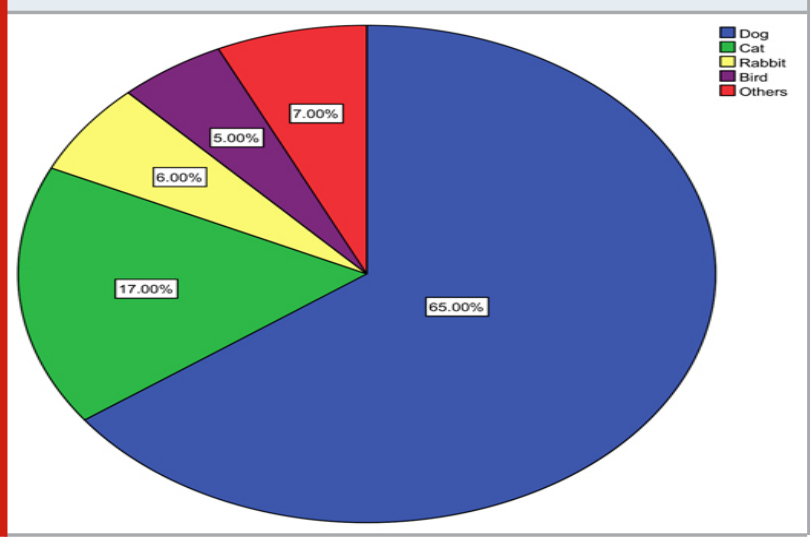

Figure 2: Pie chart showing distribution of responses to the bath cycle of the pets with Once in 15 days - 63\% being the majority of responses, Once in 30 days $-26 \%$ followed byOnce in 2 months- 7\% and Very rarely-4\%. Blue colour indicates once in 15 days, green indicates once in 30 days, yellow indicates once in 2 months and purple indicates very rarely.

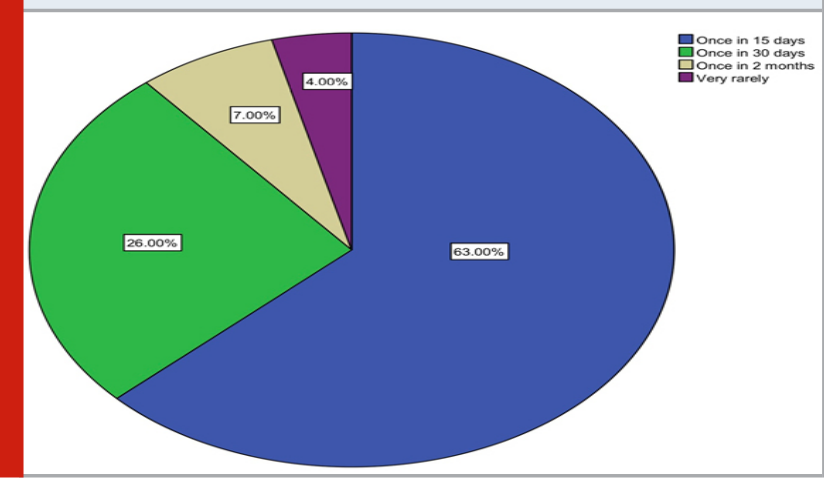


Figure 3: Pie chart showing distribution of responses regarding combing of pets in which majority of respondents $-79 \%$ responded yes and $21 \%$ dint comb . Blue colour indicates Yes and Green colour indicates No.

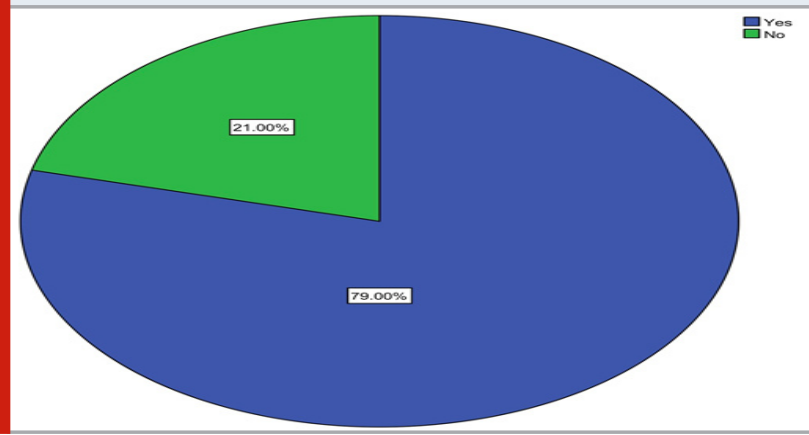

Figure 4: Pie chart showing distribution of responses regarding hair fall seen among pets in which majority of respondents - 57\% responded yes and 43\% said no. Blue colour indicates Yes and Green colour indicates No.

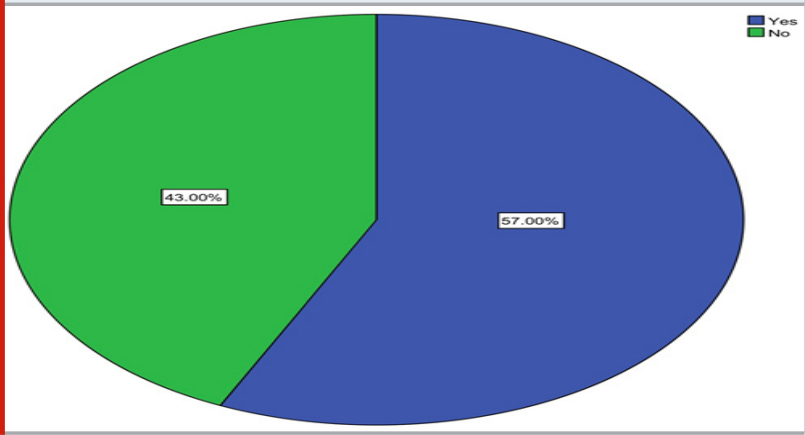

Figure 5: Pie chart showing distribution of responses regarding toilet training in pets in which majority of respondents - 83\% responded yes and 17\% said no. Blue colour indicates Yes and Green colour indicates No.

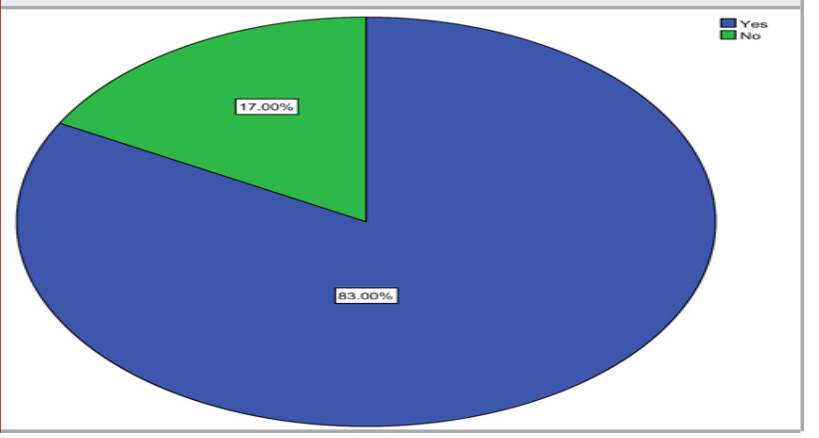

The next question was about whether the pets slept with the owners in which $67 \%$ of the participants responded yes and 33\% said no(Figure-6). 64\% of the pets lick their owners(Figure-7). Almost 65\% of pets sleep with their owners and licking them can further increase pet associated disease risks(Mani and Maguire, 2009; Patronek and Slavinski, 2009). In a question related to health, $60 \%$ of the participants take their pets to the veterinarian once in a month, $26 \%$ of participants have taken their pets to the veterinarian once in 2 months,
$11 \%$ participants have taken their pets to the veterinarian once in 6 months and 3\% participants have never taken their pets to the veterinarian(Figure-8). The next question was about the vaccination of the pet in which $81 \%$ have answered yes and 19\% have responded no(Figure-9). Vaccination against vector borne disease can save the lives of pets and humans(de la Fuente et al., 2015).

Figure 6: Pie chart showing distribution of responses regarding whether pets sleep with their owners in which majority of respondents - 67\% responded yes and 33\% said no. Blue colour indicates Yes and Green colour indicates No.

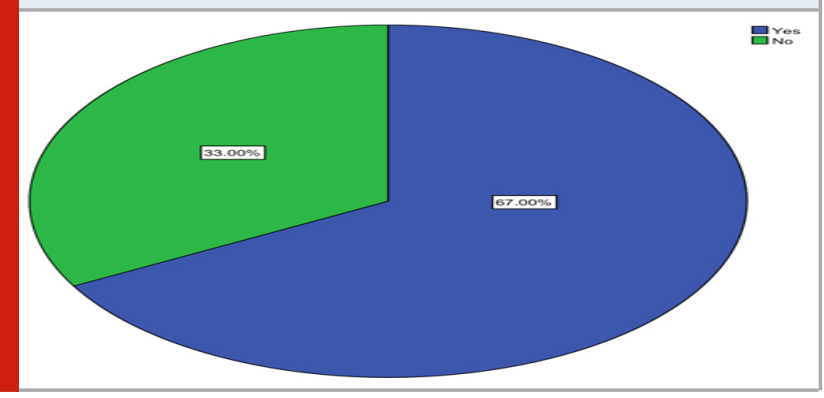

Figure 7: Pie chart showing distribution of responses regarding whether pets lick their owners in which majority of respondents $-64 \%$ responded yes and $36 \%$ said no. Blue colour indicates Yes and Green colour indicates No.

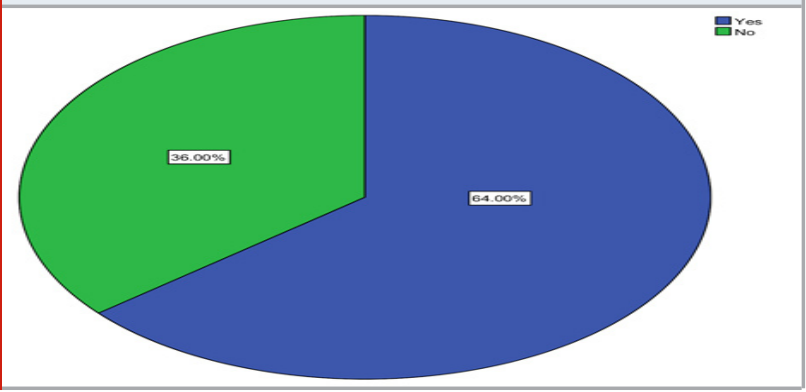

Figure 8: Pie chart showing distribution of responses to the question "How often do you take your pet to the veterinarian" with Once in a month - 60\% being the majority of responses followed by Once in 2 months $-26 \%$, Once in 6 months- $11 \%$ and Never-3\%. Blue colour indicates once in a month, green indicates once in 2 months, yellow indicates once in 6 months and purple indicates never.

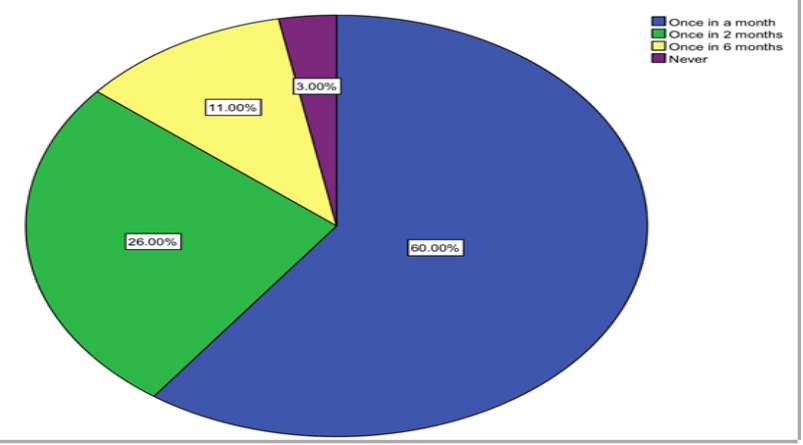


Figure 9: Pie chart showing distribution of responses regarding vaccination in pets in which majority of respondents $-81 \%$ responded yes and 19\% said no. Blue colour indicates Yes and Green colour indicates No.

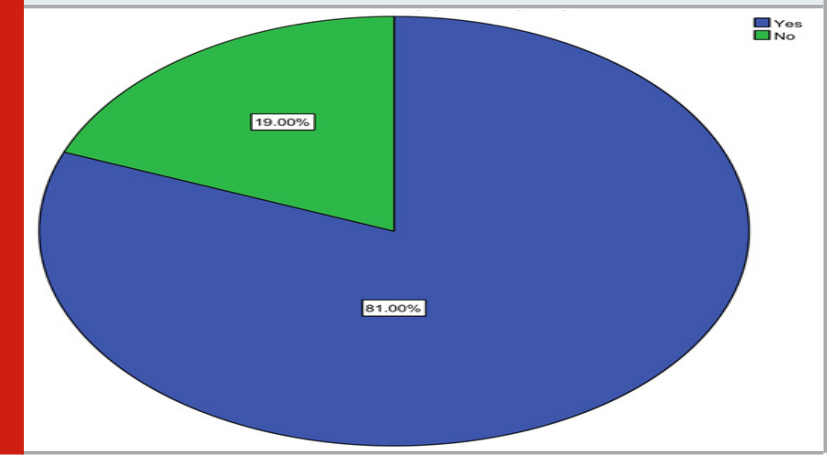

Vaccination can even save the person from any bite from the pet so that there won't be any complications like painful disfiguring wounds, infection, altered function of the affected area, and rarely death. Animal scratches can also have important physical consequences depending on the area of the body affected(Westgarth et al., 2008). Dog and cat bites are common among pet owners which are the main sources of bacterial infections. The most common bacteria transmitted by cat and dog bites are Pasteurella multocida and Pasteurella canis but the oral cavity of dogs and cats contains lots of different microorganisms which are potentially pathogenic which can be found in every animal(Damborg et al., 2016). These infections can be avoided or the chances of getting these infections decreases if the pet is vaccinated(Monath, 2013). Correlation was done between the type of pet and hairfall seen with $\mathrm{p}=0.000(\mathrm{p}<0.5)$ which is statistically significant showing that hairfall was most highly seen in dogs (Figure-10).

Figure 10- Bar graph showing association between type of pet and hairfall seen among pets. $\mathrm{X}$-axis represents the type of pet and Y- Axis represents the number of pets . Blue color indicates 'yes' to hair fall and green indicates 'no' to hair fall. Dogs were the only pets to have the complaint of hairfall than any other pets and it was statistically significant.Chi square test was done showing chi square value $=71.377$ with $p=0.000(p<0.5)$ which is statistically significant.

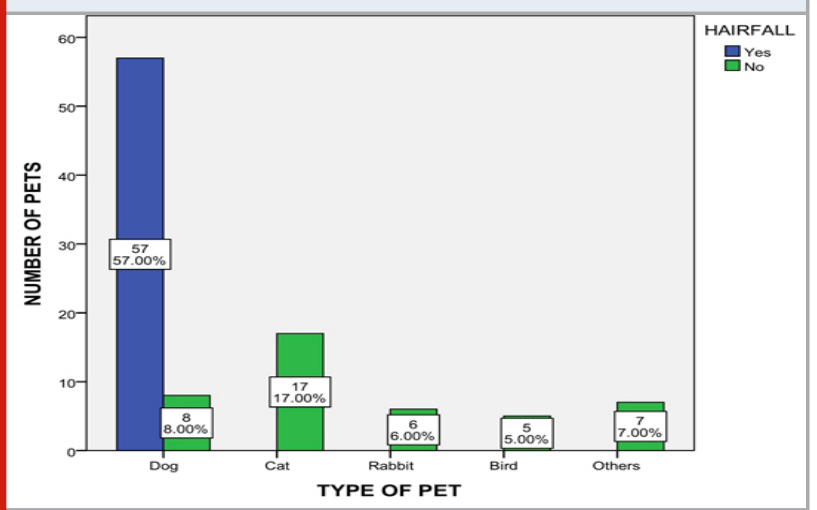

497

\section{CONCLUSION}

There are many health benefits associated with owning a pet. With pets, the owners get the opportunity to walk, socialize and relieve stress. Pets can also help manage the loneliness and depression among the owners.At the same time, if the owners don't take care of their pets hygiene, it can also lead to serious health hazards both for the pet and the owner. Thus a proper awareness has to be created on maintaining pet hygiene and its importance among the owners.

\section{ACKNOWLEDGEMENTS}

The authors would like to acknowledge the help and support rendered by the Department of Biochemistry and the Management of Saveetha Dental College and Hospitals for their constant assistance with the research.

\section{Conflict of Interest: Nil}

\section{REFERENCES}

Anderson, W. P., Reid, C. M. and Jennings, G. L. (1992) 'Pet ownership and risk factors for cardiovascular disease', The Medical journal of Australia. Wiley Online Library, 157(5), pp. 298-301.

Carmack, B. J. (1991) 'The role of companion animals for persons with AIDS/HIV', Holistic nursing practice. journals.lww.com, 5(2), pp. 24-31.

Castelli, P., Hart, L. A. and Zasloff, R. L. (2001) 'Companion cats and the social support systems of men with AIDS', Psychological reports. journals.sagepub. com, 89(1), pp. 177-187.

Conti, L. et al. (1995) 'Pet ownership among persons with AIDS in three Florida counties', American journal of public health. ajph.aphapublications.org, 85(11), pp. 1559-1561.

Damborg, P. et al. (2016) 'Bacterial Zoonoses Transmitted by Household Pets: State-of-the-Art and Future Perspectives for Targeted Research and Policy Actions', Journal of comparative pathology, 155(1 Suppl 1), pp. S27-40.

Endo, K. et al. (2020) 'Dog and Cat Ownership Predicts Adolescents' Mental Well-Being: A PopulationBased Longitudinal Study', International journal of environmental research and public health, 17(3). doi: 10.3390/ijerph17030884.

Friedmann, E. et al. (1980) 'Animal companions and one-year survival of patients after discharge from a coronary care unit', Public health reports. ncbi.nlm.nih. gov, 95(4), pp. 307-312.

Friedmann, E. and Son, H. (2009) 'The HumanCompanion Animal Bond: How Humans Benefit', The Veterinary clinics of North America. Small animal practice. Elsevier, 39(2), pp. 293-326. 
de la Fuente, J. et al. (2015) 'Prospects for vaccination against the ticks of pets and the potential impact on pathogen transmission', Veterinary parasitology, 208(1-2), pp. 26-29.

Headey, B. (1999) 'Health Benefits and Health Cost Savings Due to Pets: Preliminary Estimates from an Australian National Survey', Social indicators research. Springer, 47(2), pp. 233-243.

Herzog, H. (2011) 'The Impact of Pets on Human Health and Psychological Well-Being: Fact, Fiction, or Hypothesis?', Current directions in psychological science. SAGE Publications Inc, 20(4), pp. 236-239.

Mani, I. and Maguire, J. H. (2009) 'Small animal zoonoses and immuncompromised pet owners', Topics in companion animal medicine. Elsevier, 24(4), pp. 164-174.

Melson, G. F., Schwarz, R. L. and Beck, A. M. (1997) 'Importance of companion animals in children's lives-implications for veterinary practice', Journal of the American Veterinary Medical Association. agris.fao. org, 211(12), pp. 1512-1518.

Monath, T. P. (2013) 'Vaccines against diseases transmitted from animals to humans: a one health paradigm', Vaccine, 31(46), pp. 5321-5338.

Murray, J. K. et al. (2010) 'Number and ownership profiles of cats and dogs in the UK', The Veterinary record. British Medical Journal Publishing Group, 166(6), pp. 163-168.

Nafstad, P. et al. (2001) 'Exposure to pets and atopyrelated diseases in the first 4 years of life', Allergy. Wiley Online Library, 56(4), pp. 307-312.

Ownby, D. R., Johnson, C. C. and Peterson, E. L. (2002) 'Exposure to dogs and cats in the first year of life and risk of allergic sensitization at 6 to 7 years of age', JAMA: the journal of the American Medical Association. American Medical Association, 288(8), pp. 963-972.

Patronek, G. J. and Slavinski, S. A. (2009) 'Animal bites', Journal of the American Veterinary Medical Association. Am Vet Med Assoc, 234(3), pp. 336-345.

Perrin, T. (2009) 'The business of urban animals survey: the facts and statistics on companion animals in Canada', The Canadian veterinary journal. La revue veterinaire canadienne. Canadian Veterinary Medical Association, 50(1), p. 48.

Poresky, R. H. and Hendrix, C. (1990) 'Differential effects of pet presence and pet-bonding on young children', Psychological reports. journals.sagepub.com, 67(1), pp. 51-54.

Raina, P. et al. (1999) 'Influence of companion animals on the physical and psychological health of older people: An analysis of a one-year longitudinal study', Journal of the American Geriatrics Society. Wiley Online Library, 47(3), pp. 323-329.

Saunders, J. et al. (2017) 'Exploring the differences between pet and non-pet owners: Implications for human-animal interaction research and policy', PloS one, 12(6), p. e0179494.

Slater, M. R. et al. (2008) 'Cat and dog ownership and management patterns in central Italy', Preventive veterinary medicine. Elsevier, 85(3-4), pp. 267-294.

Traversa, D. (2013) 'Fleas infesting pets in the era of emerging extra-intestinal nematodes', Parasites \& vectors, 6, p. 59.

Westgarth, C. et al. (2008) 'Dog-human and dogdog interactions of 260 dog-owning households in a community in Cheshire', The Veterinary record. veterinaryrecord.bmj.com, 162(14), pp. 436-442. 